\title{
La Filosofía de la Arquitectura. Una aproximación epistemológica al diseño del espacio
}

\section{The Philosophy of Architecture. An epistemological approach to the design of space}

\author{
Felix Alejandro Cristiä
}

\begin{abstract}
Resumen: El proceso de diseño arquitectónico parte de una actividad mental basada en relaciones de conceptos abstractos y empíricos previos a la materialización de lo que conocemos como espacio construido y arquitectura. Este proceso no empieza en bocetos o planos, sino de manera previa en la mente mediante procesos de relaciones imaginarias (síntesis) de conceptos y analogías. La relación entre la filosofía y la arquitectura hoy no se muestra tan estrecha como en tiempos remotos, sin embargo, su comprensión cobra gran importancia para cuestionar y experimentar de la mejor manera posible los espacios en los que el ser humano crece, se desarrolla y produce su visión de mundo.
\end{abstract}

Palabras clave: Filosofía de la arquitectura, diseño arquitectónico, filosofía del espacio, teoría de la arquitectura, ciudad.

Abstract: The process of architectural design starts from a mental activity based on
relations of abstract and empirical concepts prior to the materialization of what we
know as built space and architecture. This process does not start in sketches or plans,
but in the mind in advance through processes of imaginary relationships (synthesis) of
concepts and analogies. The relationship between philosophy and architecture
nowadays maybe is not as close as in ancient times, however, the understanding of this
relationship becomes crucial in order to experience in the best possible way the spaces
in which the human being grows, develops itself and produces his/her vision of world.

* Licenciado en Arquitectura con estudios de posgrado en Filosofía por la Universidad de Costa Rica. Entre sus publicaciones recientes se encuentran: "Aproximación filosófica a la arquitectura de la Grecia antigua", Reflexiones Marginales. Revista de Filosofia, 56, 2020, y "El Genio Poético del Romanticismo temprano. La manifestación creativa como impulso hacia la infinitud". Revista de Filosofía de la Universidad de Costa Rica, 60 (157), 2021. Dirección electrónica: felix.cristia@ucr.ac.cr 
Keywords: Architecture philosophy, architectural design, philosophy of space, architecture theory, city.

—Entonces — preguntó el joven arquitecto—, ¿̇uál es la disciplina, cuál es el ritual que puede acercarnos a la psique? Porque es en esta aura sin materia ni lenguaje donde siento que el hombre verdaderamente es.

Louis Kahn

\section{Introducción}

Los métodos de exploración y diseño arquitectónico se han nutrido enormemente de las contribuciones efectuadas por y entre distintas disciplinas como la filosofía, la psicología, la antropología y la sociología. No obstante, hoy en día no se suele vincular la creación artística-práctica que implica el diseño del espacio con los campos teóricos-filosóficos. "Casi siempre falta una elaboración teórica y una crítica en el plano teórico. El respeto y la admiración por el arquitecto, mediador entre los dioses y los hombres, han paralizado la investigación teórica volviéndola superflua", ${ }^{1}$ nos dice Lefebvre. Si bien la teoría de la arquitectura ha desarrollado valiosos aportes que han abarcado temas tan diversos como la percepción, la estética o la metafísica, normalmente posee una aplicación académica centrada en el objeto construido y en el proceso de diseño, raras veces poniendo en duda los conceptos que han dado forma a los sistemas que comprende. Por consiguiente, la filosofía de la arquitectura no sólo se ocupa de la obra como objeto, sino también de su antes (el espacio mental) y de su después (las repercusiones en la vida humana); en otras palabras, la reflexión en torno a lo que se antepone a la materia y lo que va más allá de la experiencia.

Cuando se piensa en arquitectura, no es de extrañar que lo primero que llega a la mente es la imagen de alguna edificación, usando otras palabras, un objeto construido. El proceso de pensamiento que desemboca en una obra arquitectónica pertenece a una etapa pre-formal, esto es, un conjunto de

${ }^{1}$ Lefebvre, Henri, Hacia una arquitectura del placer, Madrid, Centro de Investigaciones Sociológicas, 2018, p. 143. 
conceptos y supuestos que anteceden al objeto tangible. Se ha de señalar que la arquitectura, más allá de ser una construcción o un producto, en un sentido general se trata de una respuesta. Intenta resolver una cuestión habitacional, la cual nace de una necesidad primordial: el refugio. Toda concepción arquitectónica proviene de un espacio vacío que instintivamente se proyecta en nuestra mente desde el momento en que se nos presenta la formulación del problema, y las posibilidades para transformar ese vacío representacional en el reino de las tres dimensiones son prácticamente infinitas a pesar de las limitaciones que el contexto pueda exigir.

Una vez conocido el problema, las necesidades se ramifican en nuevas incógnitas tales como: niveles, variedad y jerarquía de espacios, materiales o demografía, e inicia un proceso de selección y descarte. A partir de ellos el arquitecto crea una hipótesis, la cual puede ser planteada de distintos modos, por ejemplo, mediante bocetos. En ésta convergen tareas básicas de ordenamiento (diagramas de relaciones que conforman el programa), que junto a gran cantidad de variables tangibles (materiales, usuarios, territorio), variables intangibles (clima, reglamentación, presupuesto), y un proceso de prueba y error (diseño como experimentación) se busca llegar a la respuesta más adecuada para cada una de las necesidades impulsoras del proyecto.

El vacío se transforma en espacio habitable según procesos de adición y substracción, o siguiendo los conceptos de continuidad y discontinuidad, desembocando en gran cantidad de posibilidades de diseño que, junto a la creatividad del proyectista, da origen a una obra única. Si la hipótesis (representación del espacio) prevé la solución del problema, se podría decir que el resultado será válido; la obra erigida se someterá a la contrastación empírica para imponerse, finalmente, ante la última barrera: el tiempo. Su victoria radica en el mundo práctico; los espacios se viven, generalmente no se piensan. Esto abrió una gran puerta hacia el abordaje del espacio arquitectónico más allá de como únicamente un objeto físico.

El presente ensayo tiene por objetivo hacer una aproximación epistemológica a los conceptos del diseño del espacio que dan origen a la idea de arquitectura, por lo que primeramente expondremos algunas nociones acerca del espacio construido según distintas corrientes de pensamiento, esclareciendo la relación entre filosofía y arquitectura que influyó en los distintos modelos occidentales. Finalmente, analizaremos los conceptos por medio de los cuales forjamos nuestra noción y experiencia del espacio. La 
manera en que experimentamos el espacio arquitectónico engloba prácticamente todos los conceptos del conocimiento, de los sentidos, la razón y de la intuición, y no quedándose allí, va más allá de la experiencia, involucrando elementos como la estética, la moral o la idea de lo bello y lo bueno que forjan nuestros juicios acerca de las ciudades actuales y venideras, del hábitat humano.

\section{El lenguaje construido}

La arquitectura es la forma de la civilización. Cambia con sus movimientos sociales y se convierte en el testimonio de la era. Los distintos tipos de construcciones se articularon como respuesta a un proceso de aglomeración, interrelación y necesidad de protección, donde la convivencia entre distintas tribus, el surgimiento de la propiedad privada, la necesidad de almacenamiento de alimentos y la posibilidad de expansión hacían necesario un ordenamiento territorial bajo una misma jurisdicción.

Hoy en día la relación entre la filosofía y la arquitectura tal vez no se muestre tan evidente, pero han gozado de un fructífero mutualismo desde tiempos ancestrales, cuando los primeros sabios se empeñaron en encontrar el origen que da forma a todo lo que existe con el fin de producir sus propios medios de vida. Sus aportes fundaron una cosmovisión, una manera de explicar el mundo. El pensamiento se tornó en materia, y posteriormente, las formas que cobraba el espacio inspiraron nuevas fuentes de pensamiento.

\section{Del pensamiento al espacio}

En los albores de una humanidad curiosa, los mitos hacían su aparición cuando el conocimiento era insuficiente para explicar las fuerzas de la naturaleza y nuestro papel dentro de ella. Los medios de supervivencia eran todavía escasos, intrínsecamente ligados a un entorno aún por descifrar. Pero los asentamientos, las interrelaciones humanas con fines comerciales y la posterior expansión de los pueblos contribuyeron a forjar lo que conoceríamos por ciudades, las que brindaron nociones acerca de cómo producir y controlar las distintas manifestaciones observadas en la naturaleza. Partiendo desde el marco amplio de las ciudades, las más antiguas conocidas se construían siguiendo la topografía; los rastros encontrados en Asia Menor y en las costas del mar Egeo 
continuaban el trayecto de las montañas. En ciudades más cercanas a las costas mediterráneas y en Medio Oriente, las edificaciones seguían el sinuoso paso de las fuentes de vida: los ríos, contribuyendo a forjar su visión de mundo donde mito e historia eran prácticamente indiferenciables.

La ciudad se convirtió en la contenedora del llamado 'progreso' humano. Entre sus muros, arquitecturas y caminos se desarrollaron avances técnicos y artísticos en todas las áreas de producción. El conocimiento técnico comenzó a desplazar poco a poco las historias fantásticas donde el caos era el personaje primordial por excelencia, para dar paso a una concepción de kósmos (según su sentido griego de orden) que sigue patrones geométricos acordes a una noción de leyes universales que tratarían de ser emuladas en la pólis. ${ }^{2}$ Alcanzado el conocimiento suficiente sobre lo que le rodeaba, el ser humano se entregó a la osadía de querer invertir los roles con la naturaleza: ya no sería el entorno natural el que influenciaría el pensamiento, sino el pensamiento el que daría forma a su propio espacio. El mito -nunca extinto- se incorporó a este nuevo orden, posibilitando una multiplicidad de discursos de los que el espacio haría eco.

Si bien la obra arquitectónica comenzaría a destacarse por medio de los templos, esas casas de los dioses evidentemente más importantes que los hogares de los simples mortales, con el desarrollo de las ciudades y de la identidad que estas otorgaban a sus ciudadanos, la majestuosidad del hábitat divino sería gradualmente transferida a las instituciones que mediaban entre la ley divina y la terrenal. El aporte griego a la relación entre la arquitectura y la filosofía en Occidente se hace notable. Los primeros filósofos de la tradición occidental, los que pasarían a ser llamados 'presocráticos', introducirían el tema del arché (origen o principio), pues se habían entregado a la tarea de encontrar el elemento que daba origen a todas las cosas. La palabra 'arquitectura' proviene del latín architectūrae, y esta a su vez viene de la palabra griega architéktōn (jefe constructor). Es decir, antes del reconocimiento en nuestro lenguaje de una categoría para el diseño de edificaciones, existía la noción del arquitecto, cuya

${ }^{2}$ La pólis, palabra de origen griego, es comúnmente usada como sinónimo de ciudad, aunque no es del todo correcto. La pólis era un núcleo administrativo, o una agrupación de gente en su sentido aristotélico de ciudad-estado, mientras la ciudad lleva implícito un carácter de actividad civil de cada ciudadano que la conforma. 
raíz griega (archi, primero o jefe) es compartida con aquel principio que añoraban descubrir los primeros filósofos.

El intento por escudriñar las leyes del universo marcó rumbos de pensamiento; desde Anaximandro, para quien el mundo se encuentra suspendido en el vacío en perfecta simetría, ${ }^{3}$ pues reconoce en lo 'indeterminado' un principio de unidad; o los pitagóricos, que concebían la materia como el producto de una sucesión armónica que comenzaba por el número. ${ }^{4}$ Por esta razón la pólis se representaba como un microcosmos del universo, sometida a las mismas leyes, noción que sería compartida por artistas y matemáticos como el caso del filósofo y arquitecto Hipodamos de Mileto, considerado pionero del urbanismo.

Para los antiguos griegos, era importante formar su hábitat según conceptos de equilibrio y justicia con el fin de que la obra humana estuviera en total coherencia con el orden universal, así comienzan a nacer los 'órdenes arquitectónicos'. Esta no era una concepción arbitraria: así como la Tierra era el centro del universo, de la misma manera se convirtió el ser humano en el centro de la pólis bajo la forma del ágora. En el espacio religioso los pobladores se sentían parte de una comunidad, pero aún no tenían voz; el ágora, el espacio vacío que es identificado por lo construido que le rodea, fue revolucionario: un espacio para la libre expresión del habitante común. Aquí lo vacío se ha equiparado a lo sólido. Los griegos traerían un nuevo discurso donde el ser humano -a pesar de vivir en colectividad- era el protagonista y la arquitectura su legitimador. "El desarrollo del individualismo arquitectónico constituye la más evidente manifestación del momento en que la arquitectura comienza a convertirse en una disciplina consciente de sí misma". ${ }^{5}$ La generación de espacios 'para la gente' iba más allá de la mera funcionalidad, se trataba de crear

${ }^{3}$ Como informó Hipólito, para Anaximandro "la tierra se halla en alto, sin nada que la sostenga, pero que permanece quieta por la equidistancia de todas las cosas". Refutación de todas las herejías 1.6.1 (A 11). Citado por Bernabé, Alberto (Ed.), Fragmentos Presocráticos. De Tales a Demócrito, Madrid, Alianza, 2010, p. 57.

${ }^{4}$ Diógenes Laercio nos comenta que para los pitagóricos: "el principio de todo es la unidad (o mónada). Que de esta unidad surge la dualidad (o diada) infinita, que se establece frente a la unidad originaria como la materia (frente a la forma)". Vida de los filósofos ilustres, Libro VIII, Madrid, Alianza, 2007, p. 426.

${ }_{5}^{5}$ Alexander, Christopher, Ensayo sobre la sintesis de la forma, Buenos Aires, Infinito, 1976, p. 61. 
identidades. "La mejor arquitectura pública aspira a ser justamente eso: un lugar para el ritual que haga de cada usuario, por un breve instante, una persona más grande de lo que es en su vida diaria, llenándola de orgullo por ser de ese lugar."6

En la ciudad cada ciudadano adquiere la conciencia de que con su voz da forma a un sistema-mundo. La expresión oral transmite ideas, leyes. Es con el ejercicio del lenguaje que se crean los oficios ligados a la oratoria y la jurisprudencia, respondiendo a la necesidad de seguir manteniendo el orden (como si el caos fuera una bestia siempre al acecho). Por todo esto no se hace ilícito pensar que la ciudad, como conjunto de arquitecturas y vivencias, era el legitimador visible de lo que representaban las palabras en el ámbito invisible: el lenguaje construido. Al ser la palabra una cuestión ahora pública, algo que podía ser debatido por muchos en el ágora griega, ubicado en el centro del universo en su versión microcósmica del espacio urbano, no es raro pensar en por qué Vernant afirmaba que el sistema de la pólis implica "una extraordinaria preeminencia de la palabra sobre todos los otros instrumentos del poder. Llega a ser la herramienta política por excelencia (...)" 7 . Los códigos y reglamentos dentro del sistema, el contrato social, la construcción de la ciudadanía, han marcado la manera en que entendemos el concepto de nuestra libertad con relación al espacio.

\section{Del espacio al pensamiento}

El abordaje del espacio arquitectónico desde la óptica filosófica no es algo tan reciente, $y$, de la misma manera, la arquitectura ha fungido como recurso de pensamiento. Schelling incursionó en la percepción del arte, la música y el espacio arquitectónico. ${ }^{8}$ También lo hicieron Kant, con su analogía de la arquitectónica de la razón pura para explicar el método como un sistema

\footnotetext{
${ }^{6}$ Kostof, Spiro, Historia de la arquitectura 1, Madrid, Alianza, 1996, p. 76.

${ }^{7}$ Vernant, Jean-Pierre, Los orígenes del pensamiento griego, España, Paidós Ibérica, 1992, p. 61.

8 Para Schelling "la música en la plástica es la arquitectura". Schelling, Friedrich, Filosofía del arte, Madrid, Tecnos, p. 285). También "es la música en el espacio" (Ibid., p. 290). Cabe hacer notar que la famosa frase "la arquitectura es música congelada" es atribuida tanto a Schelling como a Goethe y a Schopenhauer.
} 
estructurado, y Schopenhauer, con su síntesis de la arquitectura basada en la oposición entre gravedad y rigidez, análoga a su concepto de voluntad y materia. Para Nietzsche "la arquitectura es una especie de elocuencia del poder expresada en formas, que unas veces convence e incluso adula y otras se limita a dar órdenes" ". Para este filósofo alemán la arquitectura no es más que una demostración de poder, poco interesada en deleitar los sentidos.

El siglo XX traería nuevas vías de discusión en las que vale la pena detenernos un poco más. Dos movimientos principales deliberaron acerca de la arquitectura, o en un sentido más abstracto, del espacio humano: por un lado, la fenomenología, donde la experiencia del sujeto desplazaba las explicaciones y donde el cuerpo, de manera integral, se posiciona como medida del espacio; y por el otro, el estructuralismo, que originalmente se ocupaba de las estructuras lingüísticas para posteriormente pasar a abordar otros campos. El estructuralismo analiza el objeto de estudio como un sistema de partes interrelacionadas, lo que a su vez genera lo que se conoce como sistemas de significación. ${ }^{10}$

La fenomenología produjo fecundos aportes en los temas de la percepción y estética. En esta rama filosófica las descripciones de las apariencias presentadas en la experiencia humana tienen más peso que las explicaciones. A diferencia de lo visto con algunos filósofos presocráticos, el fenomenólogo apunta a que no existe un principio unificador de la verdad, sino una pluralidad de verdades. Al centrarnos en las situaciones y experiencias desde el sujeto, y que se dan tanto en el ambiente construido como en la vida del ser humano, la realidad se nos revela, ya no como un conjunto de cosas que se dan por sentadas, sino como procesos siempre cambiantes que definen nuestra noción de 'ser' dentro de la colectividad. La vista, que históricamente ha ocupado un sitio privilegiado en la jerarquía de los sentidos, aquí es

${ }^{9}$ Nietzsche, Friedrich, El ocaso de los ídolos, España, Edimat, 2010, pp. 106-107.

10 Sobre este tema, resulta interesante el pensamiento del teórico Gillo Dorfles al "considerar a la arquitectura como sistema de signos; al ser una de las competencias o funciones de la arquitectura la de 'comunicar un peculiar mensaje' que se denomina mensaje arquitectónico" (Dorfles, Gillo, "Estructuralismo y semiología en arquitectura", en Jencks y Baird (comps.), El significado en arquitectura, Madrid, Blume, 1975, p. 37). Sin embargo, como veremos más adelante, sería un riesgo reducir la arquitectura a un mero sistema de signos. 
desplazada por un sistema integrado de sensaciones que reinterpreta el espacio de las prácticas humanas.

Podríamos citar la importancia que ejerció una pequeña cabaña de madera en medio de una montaña alemana para Martin Heidegger, en donde escribió Ser y Tiempo. Para Heidegger no existe espacio exterior ni interior; al hablar de ser humano ya existe la noción de que ocupa un lugar, pues el ser 'habita': "Ser hombre quiere decir: ser como mortal sobre la Tierra, quiere decir: habitar". ${ }^{11}$ No en vano el mismo filósofo expuso sus ideas acerca del 'habitar' ante un público conformado en su mayoría por arquitectos en la conferencia denominada "Construir, Habitar, Pensar", que tal vez con la excusa de tratar sobre la habitabilidad y la reconstrucción de una tierra devastada por la guerra, insinuó el rescate de la esencia humana y la reconstrucción del espíritu desquebrajado por la derrota y el sufrimiento.

A estas aproximaciones espaciales les seguirían autores como Gaston Bachelard o Henri Lefebvre. Este último, al inicio de su obra La producción del espacio, divide el espacio ideal (lógico-matemático) del social (físico), siendo que la mayoría de los filósofos se habían preocupado más que todo por el primero. Intentando superar el dualismo sujeto-objeto, entre las bases de su teoría se encuentra la tríada conceptual comprendida entre el espacio percibido (sentidos), espacio concebido (representaciones espaciales) y espacio vivido (espacios de representación). Siguiendo al filósofo francés, el espacio construido no es sólo una producción humana, sino que también es productor. De esta forma afirma que cada diseño arquitectónico o urbano obedece a un sistema que le antecede (espacio concebido), y este a su vez es el resultado de choques dialécticos anteriores que se instauran de manera presuntamente universal, a diferencia de los espacios vividos, los cuales sus usos y significados son definidos por los seres humanos en las actividades que realizan más allá de la simple habitabilidad, involucrando también tradiciones, símbolos e incluso cambiando los usos por los que estos espacios fueron erigidos, desencadenando un proceso de apropiación que genera identidad.

Los espacios de representación, vividos más que concebidos, no se someten jamás a las reglas de la coherencia, ni tampoco a las de la cohesión. Penetrados por el imaginario y el simbolismo, la historia constituye su

${ }^{11}$ Heidegger, Martin, “Construir, habitar, pensar”, Teoria, (5-6), 2016, p. 152. 
fuente, la historia de cada pueblo y la de cada individuo perteneciente a éste. $^{12}$

En tiempos más recientes podríamos pensar en la vía de discusión inaugurada por Manfredo Tafuri desde enfoques políticos y sociales. Este teórico e historiador italiano -más del lado estructuralista- afirmaba que las distintas obras arquitectónicas obedecían en primer lugar a las ideologías del poder político y económico. Por esta razón decía que no era posible que un arquitecto produjera espacios utópicos dentro de una sociedad capitalista que es en sí misma un sistema sólidamente estructurado.

La arquitectura puede hacer el esfuerzo de mantener su integridad y preservarse de la destrucción total, pero tal esfuerzo es anulado por el ensamblaje de piezas arquitectónicas en la ciudad. Es en la ciudad donde estos fragmentos son implacablemente absorbidos y privados de cualquier autonomía (...). ${ }^{13}$

Esta visión será criticada por Fredric Jameson, contribuyendo a las nuevas deliberaciones espaciales donde convergen la arquitectura y el espacio en general con las tensiones entre ideología y utopía. Para Jameson, ${ }^{14}$ la posición de Tafuri no sólo es pesimista, sino también irónicamente ideológica. A su juicio, pequeños movimientos pueden provocar transformaciones sociales. Estos movimientos y transformaciones se dan en el espacio, por lo que el espacio (arquitectónico o público) puede plantear 'futuros alternativos'.

Así, la intervención espacial, el diseño arquitectónico, la obra construída, no solamente comprenden la habitabilidad humana, sino también variables sociales, políticas y geográficas que han brindado los patrones que caracterizan a determinada época y cultura. Sin embargo, los procesos de individualización y diferenciación del trabajo a la largo de la historia fueron aspectos que condujeron a la necesidad de diseñar obras arquitectónicas que obedecieran a áreas de acción específicas, además de servir de medio para que las clases sociales más privilegiadas pudieran demostrar su capacidad de transformar la

${ }^{12}$ Lefebvre, Henri, La producción del espacio, España, Capitán Swing, 2013, p. 100.

13 Tafuri, Manfredo, Architecture and Utopia. Design and Capitalist Development, Massachusetts, The MIT Press, 1976, p. 14. Traducción propia.

${ }^{14}$ Jameson, Fredric, The ideologies of theory, Londres, Verso, 2008. 
forma de las tierras a un paso proporcional al crecimiento constante y diversificado del capital.

Finalmente, y en virtud de este breve recorrido, podemos establecer algunas definiciones que nos servirán para continuar nuestro camino. Comprenderemos la arquitectura a partir de una base: el espacio diseñado y construido por el ser humano para resolver un problema habitacional; así, cuando este espacio es apto para ser habitado, es decir, vivido, se torna espacio humano. Pero estos conceptos no se quedan únicamente en la obra arquitectónica, siendo que en conjunto los espacios arquitectónicos mutan en espacio urbano, la ciudad, el entorno artificial en el que los seres humanos han intentado modelar su propia versión del mundo. Es en el sistema de ciudades donde se amplifica la percepción humana, pues en esta convergen conceptos del espacio construido (como 'lugar de') y de libertad ('posibilidad en') que marcan principios de conducta y de desplazamiento a través del espacio.

\section{Epistemología del diseño arquitectónico}

Si anteriormente habíamos abstraído la arquitectura al espacio diseñado y construido por el ser humano con el fin de resolver un problema, ahora se hace preciso ver sus implicaciones. En un sentido general la epistemología trata sobre todos los elementos que conducen a la obtención de conocimiento, y eso incluye la reflexión o teorización relacionada con los procesos de investigación, sus problemas y componentes. A pesar de que la epistemología es a menudo situada dentro del marco del conocimiento científico, sería un error relegar la arquitectura a una mera dualidad entre técnica y arte sin relación alguna con métodos de investigación presentes en las distintas disciplinas científicas, pues no hay que olvidar que el producto-obra es el resultado de un conjunto de saberes.

Todo proceso de investigación que implica el desarrollo del diseño está basado en conceptos que se muestran válidos o necesarios para prácticamente todos los contextos en donde se ha de erigir una edificación que albergará seres humanos. Estos conceptos a su vez nacen de conocimientos proporcionados por diversos campos de investigación y son transferidos al campo de la arquitectura y del estudio del espacio. Por ejemplo, la necesidad de las fundaciones de todo edificio sigue un sistema de estructuración que implica excavación, profundidad y materiales de construcción que pueden variar según 
la ubicación; sin embargo, el acto de cimentar nace a partir de nociones 'universales' (respuestas a los procesos de investigación y del avance del conocimiento), por ejemplo, la seguridad de que lo que asciende, desciende; la certeza sobre los efectos telúricos o de la fuerza de gravedad; nociones alimentadas por la búsqueda y necesidad del ser humano de anclarse con fuerza a la tierra para asegurar su protección.

Siguiendo el pensamiento de Immanuel Kant, en la introducción de su primera Crítica afirma que la filosofía necesita una ciencia que trate de todos los conocimientos a priori y sus principios, haciendo la comparación con una edificación, la cual no podría erigirse sin haber determinado debidamente sus cimientos. La analogía se vuelve oportuna: los cimientos de toda edificación, aparte de ser la base de todo lo que apreciamos en la arquitectura, cabe hacer notar que se encuentran normalmente fuera de nuestra vista. De similar manera podríamos decir que nuestro conocimiento en cuanto al diseño y percepción del espacio se origina a partir de conceptos ya aprehendidos que albergan la síntesis y relaciones de distintos campos de investigación. En este sentido, un edificio sin la debida corroboración de sus fundaciones, es decir, sus bases, cae como todo conocimiento que pretenda darse como válido sin la demostración de sus fundamentos.

A continuación, expondremos varios de los conceptos presentes en el diseño del espacio y que, de manera similar al ejemplo de las fundaciones, nacen a partir de la síntesis de conocimientos interdisciplinarios que desembocarán en la obra arquitectónica.

\section{Tiempo y espacio}

Ahora es preciso formular la siguiente pregunta: ¿cómo es posible que podamos generar representaciones de objetos en nuestra mente, no sólo los que no hemos presenciado, sino también los que son todavía inexistentes?

Aportemos un ejemplo pertinente. Freud en su obra El malestar en la cultura hace una analogía entre la ciudad de Roma con todas las construcciones que se han alzado en ella durante su historia, y la psique como contenedora de todos los recuerdos incluyendo los que se tengan por olvidados. Siguiendo su exposición, podemos imaginar alguna ciudad como la antigua Roma, tanto las edificaciones actualmente existentes como las reconstruidas por medio de la historia, todas juntas en el mismo espacio. Somos capaces de pensar en una 
edificación demolida compartiendo el lugar con alguna otra que se encuentra actualmente en la misma localidad, y todo esto sin tan siquiera haber tenido la oportunidad de presenciarlas. El psicoanalista aludía a que una persona era capaz de abstraer sólo una imagen ante las demás según el punto de observación, comparando este hecho con la recuperación de recuerdos mediante la regresión, lo que a su vez da una idea de cómo la percepción en las ciudades cambia según el punto de atención. Freud nos comenta al respecto: "Si pretendemos representar espacialmente la sucesión histórica sólo podremos hacerlo mediante la yuxtaposición en el espacio, pues éste no acepta dos contenidos distintos". ${ }^{15}$ Esto se debe a que por mucho tiempo la sucesión era considerada un concepto del Tiempo, mientras que la simultaneidad lo era del Espacio, y juntas -aún no abandonando el pensamiento kantiano- eran condición de posibilidad para todas las representaciones.

Llegado a este punto se hace necesario esclarecer que los conceptos aquí señalados refieren al espacio abstracto mental, no al espacio-tiempo 'real' de la física contemporánea el cual es exterior a nuestra sensibilidad. No obstante, el anterior ejemplo es de gran ayuda para ilustrar la representación del espacio en nuestra imaginación. Si podemos apreciar los fenómenos, es decir, los objetos de representación en nuestra mente, se debe a que la noción de Espacio y Tiempo se dan en el sujeto de manera intuitiva a priori, es decir, no se hallan en las sensaciones. Lo anterior se debe a que para Kant, Tiempo y Espacio anteceden a cualquier representación, sirviendo de fundamento para todo fenómeno, por lo que conjuntamente hacen posible la experiencia. Al respecto nos dice: "En el espacio, pues, están determinadas o son determinables la figura, tamaño y relaciones respectivas de tales objetos". ${ }^{16} \mathrm{Y}$ por el contrario afirma: "El tiempo no puede ser determinación alguna de los fenómenos externos, no pertenece ni a la figura, situación, etc., sino que determina la relación de las representaciones en nuestros estados internos". ${ }^{17}$ Por lo tanto, el Tiempo brinda las nociones de cambio y movimiento (sucesión) que nos permite ordenar los fenómenos en el Espacio.

El hecho de que podamos imaginar una ciudad, o parte de ella, se debe a que previamente tuvimos algún tipo de experiencia (a posteriori) con el

\footnotetext{
${ }^{15}$ Freud, Sigmund, El malestar en la cultura, Madrid, Alianza, 2014, pp. 65-66.

${ }^{16}$ Kant, Immanuel, Crítica de la razón pura, Buenos Aires, Losada, 2013, p. 199.

${ }^{17}$ Ibid., p. 209.
} 
funcionamiento de las ciudades, sus edificios, las calles, los pisos, las aceras, ya sea que hemos recorrido una ciudad o la hayamos visto en imágenes, es decir, sabemos cómo funcionan porque ya hemos experimentado su funcionamiento.

\section{Del usuario (para quién) y contexto (sobre qué)}

Ahora bien, no debemos olvidar que se diseña con el fin de que la obra arquitectónica sea vivida. Es el ser humano, habitante, transeúnte, ciudadano o trabajador activo, quien le da a la arquitectura el valor de utilidad. Al usuario lo abstraeremos del concepto de sujeto, es decir, el 'yo', pues así como se diseña en función de que la obra sea usada por seres humanos, la noción de ser humano me llega primeramente desde mi propio ser. El cuerpo recibe retroalimentación del espacio en el que se mueve, y el espacio se ajusta al cuerpo. El sujeto toma el Espacio y el Tiempo mental, inmensurables, y comienza a medirlos; mediante la arquitectura se lleva a cabo este proceso. "La arquitectura es el instrumento principal de nuestra relación con el tiempo y el espacio y de nuestra forma de dar una medida humana a esas dimensiones; domestica el espacio eterno y el tiempo infinito para que la humanidad lo tolere, lo habite y lo comprenda." 18

El 'yo pienso', por lo tanto, unifica y relaciona los objetos desde mi propia psique gracias a la analogía y la síntesis que permite la imaginación. En otras palabras, yo soy la condición de posibilidad que permite que un diseño sea presuntamente tan bueno para mí como para otro ser con el que comparto especie. Podemos prefigurar, prácticamente de manera instintiva, las relaciones entre los conceptos ya vistos en el momento en que tenemos noción tanto del contexto como del problema a resolver, dando origen a representaciones espaciales o imágenes mentales que comprenden tanto los objetos del mundo exterior como los que se proyectarán sobre estos.

Cuando hablamos de contexto se hace referencia tanto al carácter espacial del lugar (por ejemplo, campo o ciudad, y sus variables naturales, climáticas o delimitaciones), como al temporal (época o acontecimientos sociales). Se trata de un lugar físico, es decir, experimentado en la práctica humana y el cual está sujeto a condiciones materiales (naturales). Con esto ya

18 Pallasmaa, Juhani, Los ojos de la piel. La arquitectura y los sentidos, Barcelona, Gustavo Gili, 2014, p. 22. 
podemos suponer que estamos abandonando los conceptos kantianos a priori de Espacio y Tiempo para adentrarnos en el espacio y tiempo (en minúsculas) como conceptos empíricos externos, que en la cotidianidad de nuestras vivencias nunca se nos presentan de manera separada, esto es, la dimensión espacio-temporal.

No obstante, sería un error pensar en el contexto únicamente como 'lugar'. "El contexto encierra a la vez lenguajes artísticos, realidades físicas, comportamientos, dimensiones urbanas o territoriales, dinámicas políticoeconómicas"19, nos dice Tafuri. Un contexto marca un espacio, no sólo físicamente, sino también junto a todos los factores que inciden sobre este; se delimita según una parte del mundo que posee características que lo hacen fácilmente reconocible o diferenciable, por lo que forma una base del proyecto la cual no se puede ignorar y que de una u otra manera brinda pautas que definen la forma que tendrá la representación en el espacio, pues "todo lo que en el mundo hace exigencias a la forma es contexto" 20 . El proyectista no puede simplemente transferir su representación mental al mundo material, no, aquí no pone las reglas. A este paso le siguen procesos de ordenamiento y experimentación con el fin de que el resultado se asemeje, lo más posible, a su idea o hipótesis.

\section{De la escala al programa}

"El hombre es la medida de todas las cosas...", la famosa frase atribuida a Protágoras que en arquitectura cobra mayor sentido. Desde el resurgimiento del humanismo tras el Renacimiento, las reglas del diseño de espacios se fueron adaptando cada vez más a nuestro cuerpo y escala, no únicamente a fungir como el reflejo del poder estatal o eclesiástico disfrazado en numerosos casos bajo la infame máscara de la monumentalidad y la desmesura. Posteriormente, en años un poco más cercanos, se hablaría de antropometría, las medidas de las cosas de acuerdo al cuerpo humano promedio, pues se adquiría conciencia de que las construcciones que habitamos deberían estar hechas para llevar a cabo nuestras funciones de la manera más cómoda y eficiente posible.

19 Tafuri, Manfredo, "La esfera y el laberinto", Instituto de arte americano e investigaciones estéticas. Seminario de crítica, 1991, p. 7.

${ }^{20}$ Alexander, Christopher, Ensayo sobre la sintesis de la forma, p. 24. 
El diseñador, al imaginar la obra a efectuar, ya posee cierta intuición acerca de la escala y proporción, pues previamente ha experimentado las formas, cantidades y cualidades de los elementos que ha podido conocer de manera empírica, por ejemplo, gracias al movimiento o al desplazamiento con respecto a distintos objetos. En otras palabras, el conocimiento empírico adquirido gracias a la relación con el mundo se convierte en ideas que reúnen la síntesis de las interacciones con los objetos, así nacen nuevos conceptos y categorías.

Ahora bien, para conocer las relaciones entre el contexto y los usos que tendrá la obra a construir según las necesidades humanas, se crea un programa. Un programa arquitectónico es una síntesis de los elementos espaciales dispuestos a resolver el problema planteado sobre el contexto. Se podría resumir el programa como la relación entre los elementos de distribución espacial. Los supuestos que los determinan nacen a partir de las necesidades del ser humano. Un programa puede representarse por medio de diagramas, cuyas relaciones se convierten en el acercamiento formal a la organización espacial que repercutirá en la disposición de la materia. Aquí comienza la transferencia desde el espacio abstracto al físico. ¿Qué es lo que un ser humano necesita mínimamente en su hogar? Un lugar para descansar, espacio para asearse, un lugar para comer, etc.; sin embargo, cabe la duda: cla existencia de los mencionados espacios es condición suficiente para cumplir con el objetivo de la habitabilidad? Desde luego que no. Es la correcta distribución de estos lo que repercutirá en el confort del usuario, y por lo tanto, en sus vivencias. Aquí comienza a nacer lo público y lo privado, así como los espacios de transición que influyen en la noción acerca de nuestra autonomía.

\section{Llenos y vacíos: la continuidad y la discontinuidad}

Las nociones de continuidad o discontinuidad ${ }^{21}$ nacen a partir de los llenos y vacíos. Las personas desarrollan el sentido de la percepción y la escala de acuerdo al ambiente en el que se desenvuelven, y éste está conformado por una 'sinfonía' de llenos y vacíos. Los primeros nos brindan límites, guías, patrones, nos permiten separar el espacio en diferentes componentes y adecuar cada uno

\footnotetext{
${ }^{21}$ Conceptos análogos a lo tectónico (por adición) y lo estereotómico (por sustracción) en la teoría de la arquitectura.
} 
a un uso en particular, mientras que los vacíos posibilitan el desplazamiento y la vivencia que han sido definidos por los llenos. Lo lleno (forma) se vuelve el contendiente del espacio, lo que dota al vacío de su significado. Al respecto, Heidegger comenta: "El puente oscila 'ligero y fuerte' sobre el río. No une solamente las orillas ya ahí existentes. En el tránsito por el puente se destacan las orillas ante todo como orillas. El puente las deja sobresalir propiamente una frente a otra. El otro lado está separado de éste por medio del puente." 22

Así, la 'cosa' puente es también un lugar, y su existencia produce al mismo tiempo la noción de otros lugares; es construcción, símbolo y conjunción espacial. Con esta escena que nos presenta el filósofo alemán podemos entender cómo mediante la disposición de la materia en el espacio se logra definir los elementos que comunican a los sentidos, modificando nuestra percepción de las cosas y brindando señales en cuanto a protección, prudencia, acceso, continuidad, autonomía, restricción. Para que los llenos y vacíos, evocadores de la continuidad y discontinuidad, puedan desembocar en obras arquitectónicas exitosas, se deben configurar de manera que respondan al programa, al mismo tiempo que a la correcta aplicación de las proporciones sobre el contexto. En este punto podemos observar que cada concepto supone la integración con el anterior, surgiendo así jerarquías conceptuales, de ahí que el proceso de diseño se nos presente como un sistema de operaciones más que de signos. El conjunto de los llenos y vacíos, en sincronía o en diacronía, forman el código que moldea el mundo en el que habitamos y dotan a cada espacio de su significado. En este sentido la famosa frase de Schelling cobra mayor fortaleza. 23

\section{Forma}

¿Qué es exactamente la forma física? ¿Será acaso la mera apariencia de una obra erigida en nuestra dimensión cuando choca con un contexto? ¿Es el conjunto de las superficies materiales que percibimos visualmente? O más bien, ¿la síntesis del proceso de diseño, es decir, la esencia de la solución que cobra vida

\footnotetext{
${ }^{22}$ Heidegger, Martin, "Construir, habitar, pensar”, p. 155.

23 "La música en la plástica es la arquitectura" (Schelling, Friedrich, Filosofía del arte, p. 285). Como vimos anteriormente, es una versión de la famosa frase "la arquitectura es música congelada”.
} 
material? ¿La forma sigue un contexto dado, o lo aplasta en cuanto puede? La forma comprende todas estas formulaciones, es el resultado de un todo. Es por medio de ella que apreciamos y distinguimos la arquitectura, que podemos diferenciarla, situarla mental y empíricamente.

Los conceptos de forma y función guardan una estrecha relación con los conceptos semiológicos de significado y significante, donde el significante vendría a ser la representación de la idea, en este caso la forma, mientras que el contenido se identifica con el significado, es decir, la cualidad y uso del espacio; o dicho de manera más breve por Louis Kahn, "La forma es el 'qué'. El diseño es el 'cómo"'. ${ }^{24}$ En este punto se hace preciso cuidarnos de no confundir forma con estilo: no se trata del conjunto de elementos estéticos que caracterizan la obra; tampoco debemos compararla con tendencia, cuyos componentes obedecen a la forma de manera efímera y superficial según acontecimientos puntuales de la historia; y finalmente, tampoco debemos confundirla con esencia, siendo esta última una abstracción, lo que prevalece de una obra al quitarle todos sus componentes sin impedir que sigamos diferenciándola. La forma es el conjunto apreciado sensorialmente, preponderantemente de manera visual, como un solo objeto.

Ahora bien, sin intentar sumergirnos en este momento dentro del mar convulso que representa la estética, se hace pertinente aclarar que un error sería reducir la forma únicamente a la mera apariencia material. ¿Sería capaz una persona desprovista del sentido de la vista apreciar una obra arquitectónica? Tal vez no apreciarla visualmente, pero la forma de la arquitectura puede ser experimentada por la misma persona. No debemos olvidar que la forma es la totalidad de los elementos, es lo lleno, pero también es vacío. Es la idea hecha materia, el significante que no debe ser relegado a únicamente un conjunto de percepciones estéticas, aunque tal vez nuestros cinco sentidos a los que estamos habituados se queden algo cortos a la hora de intentar comprender cómo experimentamos el espacio.

\section{Sistemas de percepción}

Nos disponemos a mencionar un último concepto (o bien, conjunto de conceptos) que reúne, no solo la síntesis de los anteriormente vistos, previos a

\footnotetext{
${ }^{24}$ Kahn, Louis, Forma y diseño, Buenos Aires, Nueva Visión, 2003, p. 8.
} 
la materialización de la obra, sino que también se constituyen mediante la experimentación del espacio, es decir, cuando se establece una relación entre sujeto (usuario, humano) y objeto (obra arquitectónica). En otras palabras, estamos ingresando en el mundo de lo experimentado, la 'interpretación' del espacio.

La arquitectura ha establecido, de una u otra forma, la supremacía del sentido de la vista con respecto a los demás. Con los ojos concebimos las formas siguiendo la materia, en lugar de seguir al vacío; la vista capta información de la lejanía, pero la experiencia de la arquitectura exige estar inmersa en ella. Por ello no es de extrañar que Juhani Pallasmaa vea en la arquitectura actual, occidentalizada, un cómplice de la alienación del ser humano mediante la mera exaltación visual ante un mundo cada vez más tecnológico y desvinculado del exterior. "El dominio del ojo y la eliminación del resto de los sentidos tienden a empujarnos hacia el distanciamiento, el aislamiento y la exterioridad. Sin duda, el arte del ojo ha producido edificios imponentes y dignos de reflexión, pero no ha facilitado el arraigo humano en el mundo." 25

Como afirmaron Bloomer y Moore, ${ }^{26}$ fue con el psicólogo James J. Gibson, experto en percepción visual, que se comenzó a hablar de una alternativa a los sentidos convencionales, ya que los mismos no eran suficientes para explicar la experiencia humana. Según Gibson, los sentidos no son solamente receptores de información, sino que también la buscan de manera activa, por lo que los tipos de información que maneja el cuerpo superan a la cantidad de 'aparatos sensoriales' que han podido asignarle tradicionalmente. Por consiguiente, se propone el reemplazo de los cinco sentidos a los que estamos habituados (vista, oído, olfato, gusto y tacto), a cambio de los que denominó: sistema visual, sistema auditivo, sistema gusto-olfativo, sistema de orientación y sistema háptico.

Son los últimos dos los que potencializan la percepción en cuanto a las tres dimensiones. El sistema háptico viene siendo una extensión del sentido del tacto, o mejor dicho, una integración físico-corpórea. "Actualmente numerosos arquitectos de todo el mundo proyectan con ahínco desde esta nueva conciencia e intentan volver a sensibilizar a la arquitectura mediante un

${ }_{25}$ Pallasmaa, Juhani, Los ojos de la piel. La arquitectura y los sentidos, p. 23.

${ }^{26}$ Bloomer, K. y Moore, C., Cuerpo, memoria y arquitectura, Madrid, Blume, 1983. 
sentido fortalecido de materialidad y hapticidad, textura y peso, densidad del espacio y luz materializada". ${ }^{27}$ Estos sistemas parten del supuesto de que la arquitectura se experimenta de forma integral, por lo tanto se propone el cuerpo entero, reuniendo la información externa más allá de únicamente tocar, incluyendo, por ejemplo, la tensión y la temperatura, factores que inciden en la percepción de los distintos espacios en los que habitamos y construyen nuestra noción de realidad.

\section{Conclusiones}

La historia de la arquitectura es el testimonio de la historia de la humanidad, o, dicho de otra forma, la arquitectura son las páginas en la que el ser humano ha escrito su historia. El modo en que habitamos forja la construcción de la conciencia acerca de nosotros mismos y nuestra relación con lo que nos rodea, por lo que hoy más que nunca se debe tener cautela y no dejar de preguntarnos: ¿a qué están respondiendo los espacios?

Las ciudades se iban transformando según las necesidades de sus pobladores en su constante expansión y dominio sobre la naturaleza, facilitando su convivencia. Sin embargo, sus alcances actuales no derivan únicamente de nuestra acción en sociedad, sino que son prefigurados según causas externas más allá de nuestras necesidades básicas, pues en gran medida el control social es ideológico y económico. La arquitectura es comúnmente reducida por y desde arquitectos, urbanistas o constructores a un conjunto de reglas y técnicas que dan lugar a un simple objeto material; la forma por encima de la sensación, la vista por encima del bienestar, descuidando en muchas ocasiones la repercusión que los espacios poseen en la vida de los usuarios. Pero como hemos visto, el concepto de espacio es mucho más amplio, diversificado; la responsabilidad de su diseño no se puede abstraer a una sola disciplina, menos si se olvida que el proceso involucra movimientos, no únicamente categorías estáticas.

¿Por qué hemos de fijarnos en la arquitectura desde la filosofía, o desde la metateoría? El espacio es hoy más que nunca intervenido según deseos particulares, convirtiendo cada construcción en un reflejo del productor. En las ciudades actuales los flujos, físicos (transporte) y virtuales (información)

${ }^{27}$ Pallasmaa, Juhani, Los ojos de la piel. La arquitectura y los sentidos, p. 42. 
están desplazando a los lugares (de acción). A propósito de esto David Harvey, en su libro Ciudades Rebeldes, nos comparte una visión algo pesimista sobre el espacio construido en nuestros tiempos recientes:

La ciudad tradicional ha muerto, asesinada por el desarrollo capitalista desenfrenado, víctima de su necesidad insaciable de disponer de capital sobreacumulado ávido de inversión en un crecimiento urbano raudo e ilimitado sin importarle cuáles sean las posibles consecuencias sociales, medioambientales o políticas. ${ }^{28}$

Las edificaciones que contienen a la especie humana y su desarrollo son ahora un sistema ahogado por sus propias reglas, donde las relaciones entre materia (recursos), códigos y la insaciable expansión de los mercados amenazan con establecer una única noción del habitar. La teoría de la arquitectura sugiere patrones, métodos, pero la filosofía permite cuestionarnos esos métodos, rediseñar la teoría; repensar la experiencia humana en torno al espacio que el ser humano va moldeando junto a su andar.

$\mathrm{El}$ arquitecto Louis Kahn, en el breve ensayo que inaugura su libro Forma $y$ diseño, nos habla de un joven arquitecto desconcertado que desea pedirle consejo, pues se ve incapaz de transmitir al mundo de las leyes de la naturaleza las formas que visualiza en sus sueños ${ }^{29}$. "Esta es una pregunta que se relaciona con lo mensurable y lo inconmensurable" 30 . Kahn se muestra optimista ante este interrogante: el ser humano es más grande que las obras que erige. Aconseja al joven arquitecto alejarse un poco del pensamiento y retornar al sentimiento, pero siempre con cautela, no vaya a ser que se entregue a la inacción. ¿Y qué es un arquitecto que no hace? El diseño es comprensión de una idea, es el medio que interactúa entre el sentimiento y el pensamiento, entre la mente y las emociones.

Kahn lanza una breve afirmación en la que vale la pena detenernos: aspirar más al orden que al conocimiento. Con el orden se trata de aprehender la idea, el concepto, loable meta que nos hace recordar nuevamente a los primeros filósofos, a Anaximandro, consciente de que todo cosmos es orden

${ }^{28}$ Harvey, David, Cindades rebeldes. Del derecho de la ciudad a la revolución urbana, Madrid, Akal, 2013, pp. 13-14.

${ }^{29}$ Alusión a la cita que abre el presente ensayo.

${ }^{30}$ Kahn, Louis, Forma y diseño, p. 7. 
dentro del cual se haya un origen que todavía clama por ser descifrado. La pregunta sigue abierta. Una pregunta que nos permite sacudirnos -aunque sea por breves instantes- la noción de que todo espacio que nos rodea no es más que una acumulación de materia y muros que se levantan y caen al paso de la historia de la humanidad; una historia que narra una lucha contra la naturaleza y el deseo de querer dar forma a un mundo en el que tal vez no somos más que huéspedes.

La arquitectura, sus formas y la manera de pensarla, han cambiado según el pensamiento humano en constante evolución y según nuevas necesidades que se ve obligado a suplir. Pero es mediante el diseño, es decir, ese juego donde las leyes de la naturaleza tratan de imponerse ante nuestros pensamientos - demasiado grandes para la realidad- que, a veces sin darnos cuenta, construimos nuestro ser. El diseño se encarga de ordenar lo que logra tomar del pensamiento, y la arquitectura es el testimonio. Así, el pensamiento trasciende nuestro mundo y sobrevive al paso del tiempo; sobrevive a nosotros, como letras de concreto, acero y cristal.

\section{Referencias bibliográficas}

- Alexander, Christopher, Ensayo sobre la sintesis de la forma, Buenos Aires, Infinito, 1976.

- Bernabé, Alberto (Ed.), Fragmentos Presocráticos. De Tales a Demócrito, traducción, introducción y notas de Alberto Bernabé Pajares, Madrid, Alianza, 2010.

- Bloomer, K. \& Moore, C., Cuerpo, memoria y arquitectura, Madrid, Blume, 1983.

- Diógenes Laercio,Vida de los filósofos ilustres, Madrid, Alianza, 2007.

- Freud, Sigmund, El malestar en la cultura, traducción de Ramón Rey Ardid, Madrid, Alianza, 2014.

- Harvey, David, Ciudades rebeldes. Del derecho de la ciudad a la revolución urbana, traducción de Juanmari Madariaga, Madrid, Akal, 2013.

- Heidegger, Martin, "Construir, habitar, pensar", traducción de Francisco Soler, Teoría (5-6), 2016, pp. 150-162.

- Jameson, Fredric, The ideologies of theory, Londres, Verso, 2008. 
- Jencks, C. y Baird, G. (Eds.), El significado en arquitectura, Madrid, Blume, 1975.

- Kahn, Louis, Forma y diseño, Buenos Aires, Nueva Visión, 2003.

- Kant, Immanuel, Crítica de la razón pura, traducción de José del Perojo y José Rovira Armengol, Buenos Aires, Losada, 2013.

- Kostof, Spiro, Historia de la arquitectura 1, Madrid, Alianza, 1996.

- Lefebvre, Henri, Hacia una arquitectura del placer, Madrid, Centro de Investigaciones Sociológicas, 2018.

- Lefebvre, Henri, La producción del espacio, Traducción de Emilio Martínez, España, Capitán Swing, 2013.

- Nietzsche, Friedrich, El ocaso de los ídolos, España, Edimat, 2010.

- Pallasmaa, Juhani, Los ojos de la piel. La arquitectura y los sentidos, Barcelona, Gustavo Gili, 2014.

- Schelling, Friedrich, Filosofía del arte, Madrid, Tecnos, 1999.

- Tafuri, Manfredo, Architecture and Utopia. Design and Capitalist Development, Massachusetts, The MIT Press, 1976.

- Tafuri, Manfredo, "La esfera y el laberinto", Instituto de arte americano e investigaciones estéticas, Seminario de crítica, 1991.

- Vernant, Jean-Pierre, Los orígenes del pensamiento griego, España, Paidós Ibérica, 1992.

Recibido: 08/2019. Aceptado: 04/2020 